\title{
THE EFFECT OF THE ASSUMED INTEREST RATE AND SMOOTHING ON VARIABLE ANNUITIES
}

\author{
BY
}

\author{
ANNE G. BALTER (D) AND BAS J. M. WERKER
}

\begin{abstract}
In this paper, we consider the risk-return trade-off for variable annuities in a Black-Scholes setting. Our analysis is based on a novel explicit allocation of initial wealth over the payments at various horizons. We investigate the relationship between the optimal consumption problem and the design of variable annuities by deriving the optimal so-called assumed interest rate for an investor with constant relative risk aversion preferences. We investigate the utility loss due to deviations from this. Finally, we show analytically how habit-formation-type smoothing of financial market shocks over the remaining lifetime leads to smaller year-to-year volatility in pension payouts, but to increases in the longer-term volatility.
\end{abstract}

\section{KEYWORDS}

Optimal consumption, certainty equivalent loss, variable annuities, assumed interest rates, conversion risk, smoothing financial market shocks.

JEL codes: G22, G23, J26, D81.

\section{INTRODUCTION}

Over the past few decades, defined benefits pension schemes have largely been converted into defined contributions pension schemes without or with lower guarantees. Especially the recent financial crisis and increasing life expectancies affect the sustainability of pension systems that include guarantees. Therefore, there is a rising ${ }^{1}$ number of products available in the market that explicitly let these risks be borne by the individual rather than the employer or insurer. If the pension payments in the decumulation phase include risk, we refer to these designs as variable annuities. Fixed annuities are those for which the payments are not uncertain. 
There is a wide literature on variable annuities including investigating different embedded guarantees (Mahayni and Schneider, 2012; Chen et al., 2015), pricing variable annuities (Bauer et al., 2008; Bacinello et al., 2011; Nirmalendran et al., 2014), hedging variable annuities (Coleman et al., 2006; Trottier et al., 2018) or combinations of these (Kling et al., 2011; Bernard et al., 2014). Moreover, optimal demand for different annuity products is also investigated (Horneff et al., 2009; Blake et al., 2014; Peijnenburg et al., 2016). Designs in which equity exposure is incorporated in the annuity product is shown to increase welfare by, for example, Koijen et al. (2011).

We investigate variable annuities, where the variability arises due to risky investment returns. We study the relationship between the so-called assumed interest rate (AIR) and the (expected) annuity payments. The AIR effectively determines the decumulation speed of financial wealth over the payout phase: a larger AIR leads to higher early payments and lower later payments. In case the AIR equals the expected return on the underlying portfolio, the income during the payout phase is, in expectation, constant. See Dellinger (2006) and Horneff et al. (2010) for more details on the usage of the AIR concept in insurance pricing. We provide a novel way to solve the optimal consumption problem and, in doing so, derive the AIR that optimizes lifetime utility of consumption. We also analyze the utility loss of investors with constant relative risk aversion (CRRA) preferences who allocate their wealth suboptimally over their life cycle and/or have a suboptimal risk exposure. Under the assumption of an optimally chosen risk exposure, we find that a restriction to a (suboptimal) constant expected pension income does not lead to large utility losses. We also show that pension payments with a horizon of "only" 10 years are fairly insensitive to the choice of the AIR. As a result, unlike common practice, communication about the effect of choosing an AIR is preferably based on results for horizons closer to 20 years. We also investigate how financial shocks can be smoothed and what the effect is on the variable annuity. In that case, we find that a horizon-dependent AIR ensures a constant expected pension income.

It is well known that CRRA investors prefer to absorb financial shocks immediately in their consumption rather than smoothing the effect across future consumption. This follows as the optimal consumption is a constant fraction of the wealth level and thus a shock in wealth leads one-to-one to a shock in consumption. Nonetheless, we investigate the impact of smoothing in variable annuities and show how a stable expected pension payment can be attained within this setting. Maurer et al. (2016) and Guillén et al. (2006) investigate smoothing in collective pension plans with both intergenerational risk transfers and risk-sharing between pension providers and holders. We abstain from wealth transfers between retirees and insurers, and focus on the method to smooth within the retiree's own available wealth. Bruhn and Steffensen (2013) show that habit formation preferences can explain the demand for such collective smoothing designs.

Our approach to smoothing financial market shocks is novel. More precisely, we consider strategies that lead to smooth consumption paths. The term 
smoothing refers to a preference for smooth consumption paths in habit formation like specifications. Such preferences lead to spreading out financial shocks and, thus, being less exposed to large upside and downside risk on short horizons. As mentioned above, we explicitly separate the allocation of initial (pension) wealth to pension payments at various horizons. We call these "pension buckets" for the given horizons. Given the allocation of pension wealth to the individual pension buckets, each investment problem is a standard final-wealth problem whose properties are well studied that started with the seminal work of Merton (1969) and Cox and Huang (1989). Smoothing is then implemented by reducing the stock allocation for the pension bucket in the final years before the horizon. Up to our knowledge, this paper is new in its approach toward smoothness. The possibility of smoothing financial market returns has been incorporated in many products in order to allow for preferences that exhibit habit formation. Smoothing financial market returns essentially means that a decrease of, say, $10 \%$ in pension wealth needs not be translated immediately into a decrease of $10 \%$ in pension payments. This implies that pension payments will decrease, due to this adverse financial market development, at a slower pace, but ultimately by more than $10 \%$. We explicitly model this possibility and show how it influences the risk-return trade-off for variable pension payments. In order to design the annuity such that constant nominal expected pension payments are obtained, we show that smoothing leads to a horizon-dependent AIR.

The rest of this paper is organized as follows. In Section 2, we investigate the risk-return trade-off for variable annuities by deriving the AIR that leads to constant expected pension payments, the optimal AIR for a CRRA investor and the utility loss between these. In Section 3, we consider how to smooth financial market shocks. And Section 4 concludes the paper. As numerical illustration, we provide a running example throughout the paper.

\section{VARIABLE ANNUITIES}

The financial market that we consider is described by the seminal work of Merton (1971). This implies that in the standard Black-Scholes/Merton setting there is a risk-free asset with a constant interest rate $r$, there is a risky asset with price $S_{t}$ at time $t$ that evolves by the diffusion process

$$
\begin{aligned}
\mathrm{d} S_{t} & =\mu S_{t} \mathrm{~d} t+\sigma S_{t} \mathrm{~d} Z_{t} \\
& =(r+\lambda \sigma) S_{t} \mathrm{~d} t+\sigma S_{t} \mathrm{~d} Z_{t} .
\end{aligned}
$$

Thus, we assume that the stock price $S_{t}$ follows a geometric Brownian motion, where $\mu$ stands for the expected return, $\sigma$ is the stock volatility, $\lambda$ is the Sharpe ratio

$$
\lambda=(\mu-r) / \sigma,
$$

and $Z$ is a standard Brownian motion on the probability space $(\Omega, \mathcal{F}, \mathbb{P})$. 
Moreover, we assume the isoelastic (power) function for utility that exhibits a CRRA and is given by

$$
u(x)= \begin{cases}\frac{x^{1-\gamma}}{1-\gamma} & \text { if } \gamma>0, \gamma \neq 1, \\ \ln (x) & \text { if } \gamma=1,\end{cases}
$$

where $\gamma$ is the relative risk aversion level. The more risk averse the investor is, the higher $\gamma$. We exclude negative risk aversion levels which would imply risk loving preferences. Since additive constant terms in objective functions do not affect optimal decisions, a term of minus one is omitted from the numerator which would be needed to show that the limiting case of $\gamma$ to one converges to logarithmic utility.

In general, the investor is endowed with initial wealth $W_{0}$ which can be used for consumption and the remainder is invested in the financial market. The wealth process is given by

$$
\mathrm{d} W_{t}=\left(\left(r+w_{t}(\mu-r)\right) W_{t}-c_{t}\right) \mathrm{d} t+\sigma w_{t} W_{t} \mathrm{~d} Z_{t},
$$

where $w_{t}$ is the fraction invested in the risky asset and $c_{t}$ is the withdrawal (consumption) rate. For the CRRA utility function, the optimal time-varying risk exposure $w_{t}$ is known to be

$$
w^{*}=\frac{\lambda}{\gamma \sigma}
$$

see, for example Theorem 3.8.8. in Karatzas and Shreve (1998). That is, the optimal exposure is state- and time-independent. Concerning the optimal consumption choice, we represent the withdrawal via the AIR which determines the allocation of initial wealth to the (optimal) consumption at various horizons. We formulate this problem using a discrete number of consumption dates which effectively means that we solve $H$ separate terminal wealth problems. The novelty in this setup allows us to directly cast optimal consumption questions into AIRs in variable annuities.

As an example, consider a retiree who enters retirement with total wealth $W_{0}$ at time 0 and who needs to finance $H$ annual pension payments at times. For ease of exposition, we assume $H$ to be given; that is, we consider fixedterm instead of lifelong variable annuities. Think of $H$ as the remaining life expectancy at retirement age. ${ }^{2}$

The pension payments at each horizon $h=0, \ldots, H-1$ have to be financed from the initial total pension wealth $W_{0}$. This simple idea is formalized by the notation in the next definition.

Definition 2.1. Let $W_{0}(h)$ be the amount reserved at time 0 that finances (through a self-financing strategy) the consumption in year $h$. 
The budget constraint now implies

$$
W_{0}=\sum_{h=0}^{H-1} W_{0}(h) .
$$

Stated otherwise, at time 0 we consider an amount of wealth $W_{0}(h)$ that is available to finance the pension payment at time $h$. The actual pension payment will, of course, depend on the investment strategy that is followed and the financial market returns. We can, conceptually, allow for a different investment strategy for the wealth allocated to each horizon $h=0, \ldots, H-1$. This is indeed precisely what happens when financial market returns are smoothed; see Section 3.

The way total pension wealth $W_{0}$ is allocated over all pension buckets $W_{0}(h)$ determines implicitly the so-called AIR $a_{0}(h)$.

Definition 2.2. The AIR at time 0 for horizon $h, a_{0}(h)$, is defined by

$$
\frac{W_{0}(h)}{W_{0}(0)}=\exp \left(-h a_{0}(h)\right) \text {. }
$$

Jointly with the total wealth $W_{0}$ available in (2.7), this implies

$$
\frac{W_{0}(h)}{W_{0}}=\frac{W_{0}(h)}{\sum_{k=0}^{H-1} W_{0}(k)}=\frac{\exp \left(-h a_{0}(h)\right)}{\sum_{k=0}^{H-1} \exp \left(-k a_{0}(k)\right)} .
$$

Intuitively, this relation determines the fractions of total wealth allocated to the various horizons $h$. Note that $a_{0}(h)$ generally does not need to be constant in $h$; that is, there can be an AIR term structure or, equivalently, a horizondependent AIR. This will become particularly relevant when discussing the possibility of smoothing in Section 3.

We introduce a running example that is used as illustration throughout this paper with the following parameters: the expected return is $\mu=6.00 \%$, the stock volatility is $\sigma=20.00 \%$ and the risk-free interest rate is $r=2.00 \%$, which leads to a Sharpe ratio of $\lambda=0.20$. We fix the horizon at $H=20$ years. The initial wealth is assumed to be equal to $W_{0}=€ 100,000$. Figure 1 shows, for two different AIRs, the percentage of total wealth $W_{0}$ that is allocated to each horizon; that is, we depict $W_{0}(h) / W_{0}$ as given by (2.9).

Let us, for the sake of illustration and before turning to variable annuities, briefly review fixed annuities. We assume that the wealth $W_{0}(h)$ for each horizon $h$ is completely invested in a risk-free bank account. Using an AIR of $2.00 \%$, that is equal to the prevailing risk-free rate $r$, implies that each subsequent bucket that is allocated to a specific year contains $2.00 \%$ less of the initial wealth than the previous bucket; see the solid bars in Figure 1. Since each bucket will grow each year at the risk-free rate, we ultimately get a constant stream of pension payments. The initial allocation to the first bucket will 


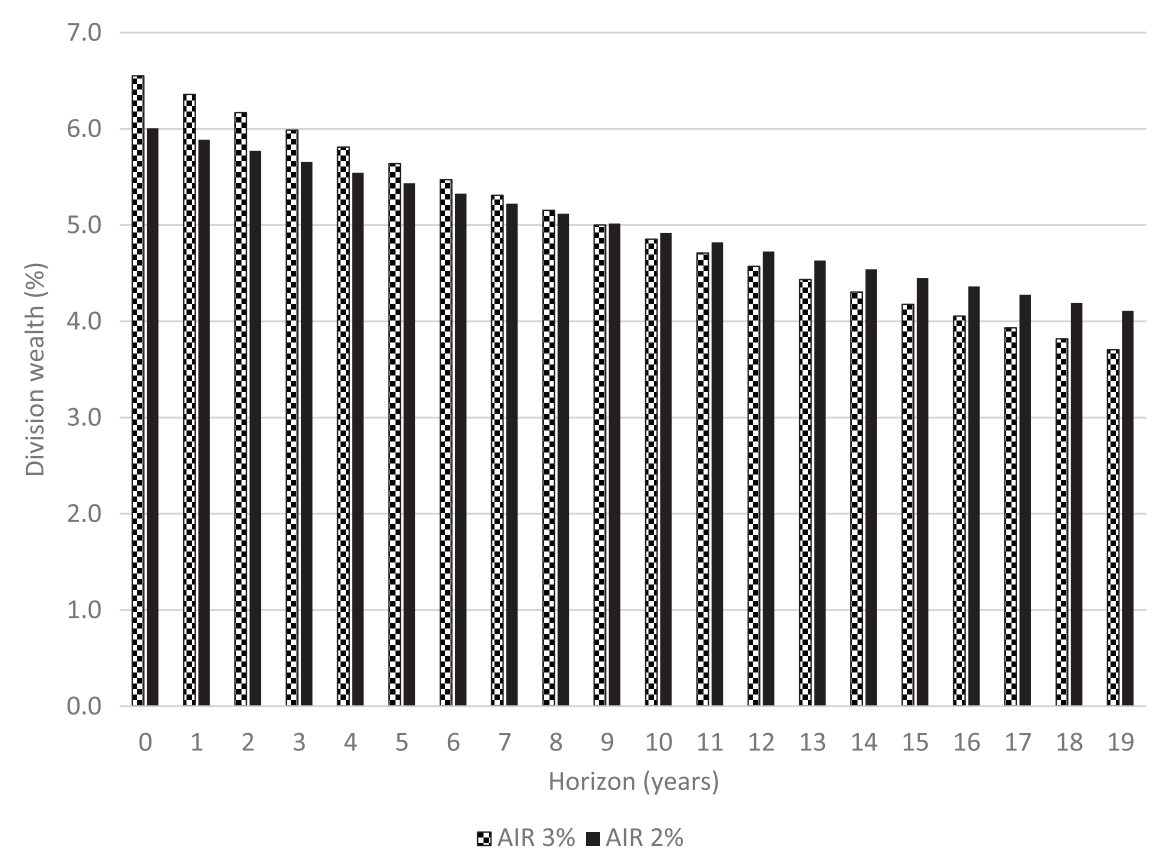

FIGURE 1: Wealth division for $a_{0}(h)=2.00 \%$ and $a_{0}(h)=3.00 \%$ for all $h \in[0, \ldots, 19]$.

be largest since it will not earn any interest income, while the second bucket can contain $2.00 \%$ less since the additional income from interest for 1 year is also $2.00 \%$.

Now consider the blocked bars in Figure 1, which is based on an AIR of $a_{0}(h)=3.00 \%$. In this case, each subsequent bucket will contain $3.00 \%$ fewer initial wealth than the previous one. As a result, more wealth is allocated to earlier payments and less to later payments. Stated differently, since the initial total wealth $W_{0}$ is given, the higher earlier payments will lead to lower later payments. This is visible in Figure 1, where the blocked bar compared to solid bars imply that the first payment is $9.1 \%$ higher while the last payment is $9.8 \%$ lower. In terms of pension payments, an entirely risk-free investment would lead to a $r=2.00 \%$ return every year. As a result, pension payments will decrease by $3.00 \%-2.00 \%=1.00 \%$ every year.

Now, let us consider what happens in case each of the buckets is not invested risk free but partly in the risky stock $S_{t}$. That is, we invest each $W_{0}(h)$ in a continuously re-balanced strategy with a stock exposure $w$. Standard calculations then show that wealth $W_{t}(h)$, for the pension payment at time $h$, evolves as

$$
\mathrm{d} W_{t}(h)=(r+w \lambda \sigma) W_{t}(h) \mathrm{d} t+w \sigma W_{t}(h) \mathrm{d} Z_{t},
$$




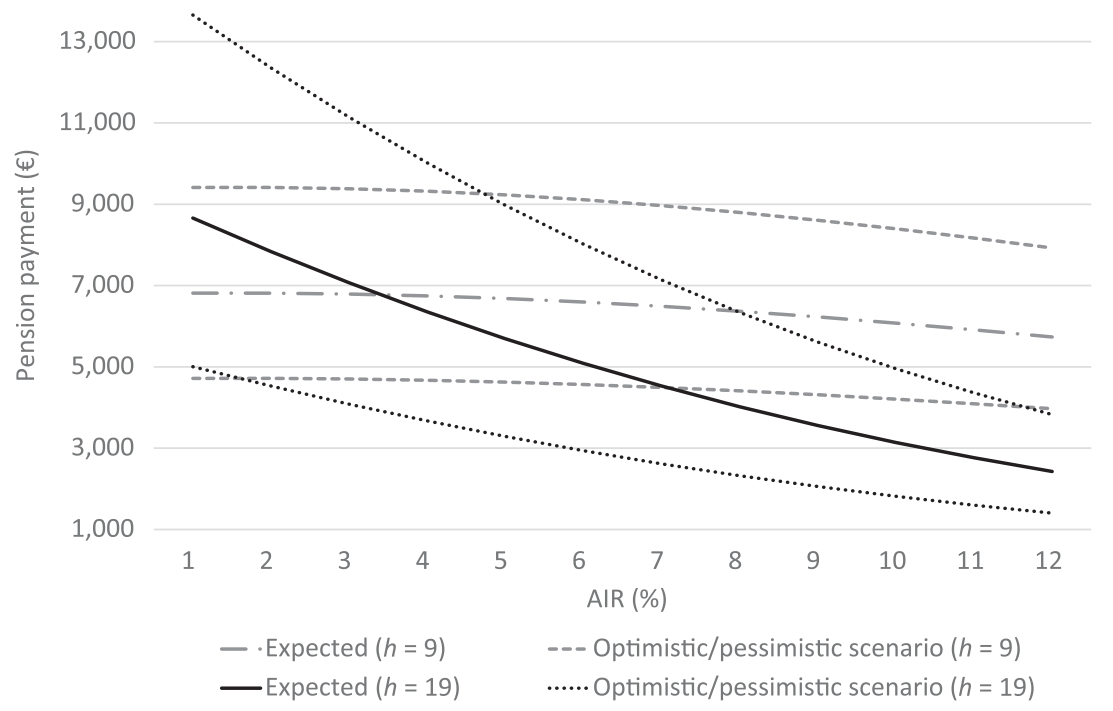

FIGURE 2: Sensitivity AIR.

for $0 \leq t \leq h$. For an investment mix of $w$, the expected pension payment of a variable annuity at horizon $h$ is given by

$$
\mathbb{E}_{0}\left[W_{t}(h)\right]=W_{0}(h) \exp (t(r+w \lambda \sigma)) .
$$

The quantile at level $\alpha$ is given by

$$
Q_{0}^{(\alpha)}\left(W_{t}(h)\right)=W_{0}(h) \exp \left(t\left(r+w \lambda \sigma-\frac{1}{2} w^{2} \sigma^{2}\right)+z_{\alpha} \sqrt{t} w \sigma\right),
$$

where $z_{\alpha}$ denotes the corresponding quantile of the standard normal distribution. Note that the risk exposure that is constant per bucket can easily be extended to time-varying risk exposure, though optimality is obtained for a constant $w$.

Remark 2.1. Figure 2 shows the sensitivity of the AIR on the expected pension payment at $h=9$ and $h=19$. We observe that an increase in the AIR has hardly any effect on the distribution of the 10th pension payment, but all the more on the 20 th payment. The higher the AIR, the larger the expected payments in the near future and the lower the expected payments in the distant future, with the expected payments in the middle of the horizon being hardly influenced by the choice of $A I R$.

Remark 2.2. Contrary to popular belief, a variable annuity does not provide protection against interest rate risk upon conversion of initial pension wealth $W_{0}$ into an annuity. Conversion risk is also known as annuity risk, that is, the risk that if 
financial market conditions are unfavorable at retirement, annuities are relatively expensive. Both for fixed and variable annuities, the level of the interest rates at the moment of conversion plays an important role. Although we do not explicitly consider a market with interest rate risk, we can assess the conversion risk effect by studying the implications of changes in the risk-free rate $r$.

In general $W_{0}(h)=\frac{W_{0} \exp \left(-h a_{0}(h \mid w)\right)}{\sum_{k=1}^{H-1} \exp \left(-k a_{0}(k \mid w)\right)}$ holds, which we obtain by slightly rewriting (2.9). For the fixed annuity, the pension payments are known to be equal to $W_{h}(h)=W_{0}(h) \exp (r h)$, while for the variable annuity, $\mathbb{E}_{0}\left[W_{h}(h)\right]=$ $W_{0}(h) \exp ((r+w \lambda \sigma) h)$. And thus a change in the risk-free rate from $r$ to $r^{\prime}$ and in the AIR from a to $a^{\prime}$ leads to an equal shock in all payments of

$$
\frac{\left.W_{h}(h)\right|_{r}}{\left.W_{h}(h)\right|_{r^{\prime}}}=\frac{\left.\mathbb{E}_{0}\left[W_{h}(h)\right]\right|_{r}}{\left.\mathbb{E}_{0}\left[W_{h}(h)\right]\right|_{r^{\prime}}}=\exp \left(\left(r-r^{\prime}+a^{\prime}-a\right) h\right) \frac{\sum_{k=1}^{H-1} \exp \left(-k a^{\prime}\right)}{\sum_{k=1}^{H-1} \exp (-k a)} .
$$

The only viable way of dealing with conversion risk is to use appropriate lifecycle investment strategies (in terms of bond duration) during the accumulation phase (Koijen et al., 2011). Products such as guaranteed annuity options (Kling et al., 2014) guarantee the policyholder at the start of the deferred annuity a minimum conversion factor or a minimum pension income both circumventing the risk of expensive lifelong annuities at the retirement age. However, the rate is fixed at an earlier date at which market conditions can also be unfortunate.

\subsection{Constant expectation AIR}

One may be interested to choose the AIR $a_{0}(h)$ in such a way that the expected pension payments are constant with respect to $h$, that is such that $\mathbb{E}_{0}\left[W_{h}(h)\right]=$ $W_{0}(0)$ (recall that the first pension payment $W_{0}(0)$ is without investment risk).

Proposition 2.1. The AIR $\bar{a}_{0}(h \mid w)$ that leads to constant expected payments for variable annuities equals

$$
\bar{a}_{0}(h \mid w)=r+w \lambda \sigma
$$

Proof. From (2.11), we find that $\mathbb{E}_{0}\left[W_{h}(h)\right]=W_{0}(0)$ implies

$$
\frac{W_{0}(h)}{W_{0}(0)}=\exp (-h(r+w \lambda \sigma))
$$

or (2.14), using (2.8).

This constant AIR leads to nominally constant expected pension payments. In case our financial market would exhibit interest rate risk (that is, a horizondependent risk-free term structure) and/or stock market predictability, we 
12,000
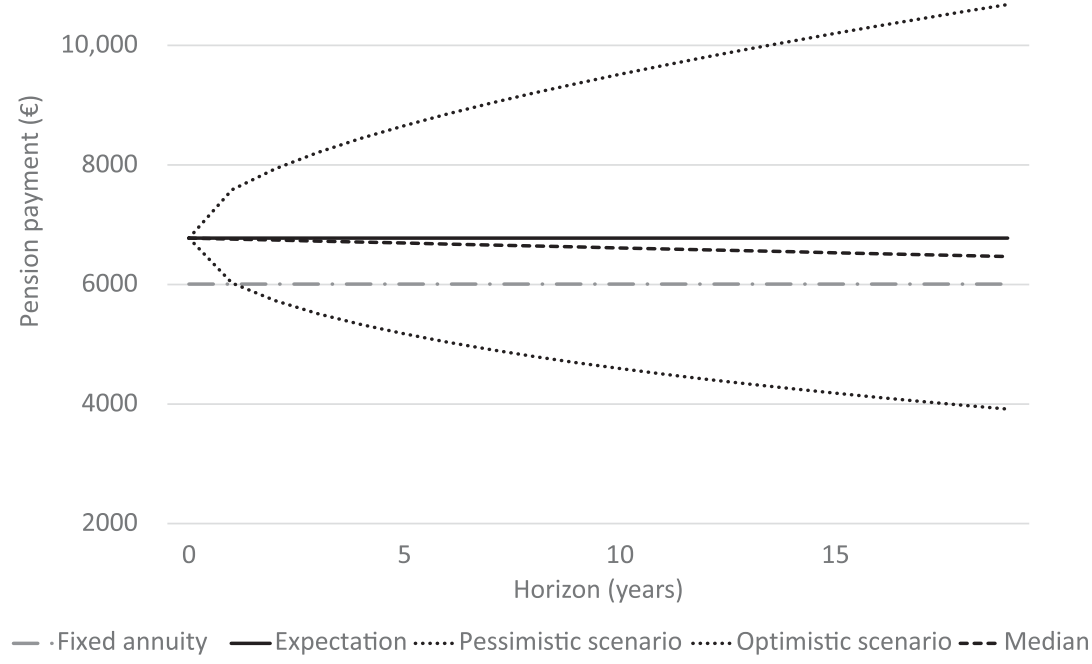

FIGURE 3: Variable annuity with $w=35 \%$ and $\bar{a}_{0}(h \mid w)=3.4 \%$.

would need horizon-dependent AIRs to obtain expected constant pension payments. We will see that, even in the present financial market, also smoothing financial market returns leads to a horizon-dependent AIR if annuity payments are required to be constant in expectation.

Figure 3 shows, in solid black, the expected yearly pension payment with a stock exposure $w=35 \%$ and the $5 \%$ and $95 \%$ quantiles. If the AIR equals the expected return as in (2.14), then a constant stream of expected pension payments is obtained. The median is (slightly) below the expected pension payments since the log-normal distribution is skewed. The difference between the variable and the fixed annuity is caused by the risk included in the variable annuity. As a result, the variable annuity leads to higher expected payments, but there is the risk that the realized payments are actually lower than the fixed annuity. The dash-dotted line is the fixed annuity in which $W_{0}(h)$ is fully invested in the risk-free asset.

\subsection{Optimal AIR}

For given preferences, we derive the optimal AIR that maximizes the expected utility from all the pension payments subject to the budget constraint of the total available pension wealth. The optimal withdrawal is determined by the optimal allocation strategy $a_{0}^{*}(h \mid w)$. The retiree has to determine how much of his wealth he allocates to each horizon for a given investment strategy $w$. Thus, a retiree who maximizes the expected utility subject to the budget constraint solves the following optimization problem: 


\section{Problem 2.1.}

$$
\begin{aligned}
& \max _{\left\{W_{0}(h)\right\}} \mathbb{E}_{0}\left[\sum_{h=0}^{H-1} \exp (-\beta h) u\left(W_{h}(h)\right)\right] \\
& \text { s.t. } \quad W_{0}=\sum_{h=0}^{H-1} W_{0}(h),
\end{aligned}
$$

where $\beta$ is the subjective discount rate that reflects time preferences, that is, impatience.

Proposition 2.2. The optimal AIR that solves Problem 2.1 with utility function (2.4) is

$$
a_{0}^{*}(h \mid w)= \begin{cases}r+\frac{1}{\gamma}(\beta-r)-\left(\frac{1}{\gamma}-1\right) w \sigma\left(\lambda-\frac{1}{2} \gamma w \sigma\right) & \text { if } \gamma>0, \gamma \neq 1, \\ \beta & \text { if } \gamma=1 .\end{cases}
$$

Proof. Using Itô's lemma and (2.10), we find

$$
\mathrm{d} W_{t}(h)^{1-\gamma}=\left(r+w \lambda \sigma-\frac{1}{2} \gamma w^{2} \sigma^{2}\right)(1-\gamma) W_{t}(h)^{1-\gamma} \mathrm{d} t+w \sigma(1-\gamma) W_{t}(h)^{1-\gamma} \mathrm{d} Z_{t} .
$$

This leads to the optimization problem

$$
\begin{aligned}
& \max _{\left\{W_{0}(h)\right\}} \sum_{h=0}^{H-1} \exp (-\beta h) \frac{W_{0}(h)^{1-\gamma}}{1-\gamma} \exp \left(\left(r+w \lambda \sigma-\frac{1}{2} \gamma w^{2} \sigma^{2}\right)(1-\gamma) h\right) \\
& \text { s.t. } W_{0}=\sum_{h=0}^{H-1} W_{0}(h) .
\end{aligned}
$$

The Lagrangian is

$$
\begin{aligned}
\mathcal{L}\left(W_{0}(h)\right)= & \sum_{h=0}^{H-1} \exp (-\beta h) \frac{W_{0}(h)^{1-\gamma}}{1-\gamma} \exp \left(\left(r+w \lambda \sigma-\frac{1}{2} \gamma w^{2} \sigma^{2}\right)(1-\gamma) h\right) \\
& -\kappa\left(\sum_{h=0}^{H-1} W_{0}(h)-W_{0}\right) .
\end{aligned}
$$

For ease of notation, let $f(h)=\exp \left(-\beta h+\left(r+w \lambda \sigma-\frac{1}{2} \gamma w^{2} \sigma^{2}\right)(1-\gamma) h\right)$. Then the first-order condition with respect to $W_{0}(h)$ becomes

$$
\begin{aligned}
\frac{\partial \mathcal{L}\left(W_{0}(h)\right)}{\partial W_{0}(h)} & =W_{0}(h)^{-\gamma} f(h)-\kappa=0, \\
W_{0}^{*}(h) & =\kappa^{-\frac{1}{\gamma}} f(h)^{\frac{1}{\gamma}} .
\end{aligned}
$$


The Lagrangian multiplier can be solved by plugging the optimal wealth allocation in the budget constraint, implying

$$
\left(\kappa^{*}\right)^{-\frac{1}{\gamma}}=\frac{W_{0}}{\sum_{h=0}^{H-1} f(h)^{\frac{1}{\gamma}}} .
$$

Combining (2.23) and (2.24) gives

$$
W_{0}^{*}(h)=f(h)^{\frac{1}{\gamma}} \frac{W_{0}}{\sum_{h=0}^{H-1} f(h)^{\frac{1}{\gamma}}} .
$$

By the definition of the AIR in Equation (2.9), the optimal AIR equals

$$
a_{0}^{*}(h \mid w)=-\frac{1}{h} \ln (f(h))^{\frac{1}{\gamma}} .
$$

Note that both $\bar{a}_{0}(h \mid w)$ and $a_{0}^{*}(h \mid w)$ are independent of $h$. Thus because the problem is time consistent, it is never optimal to transfer money from year to year; that is, re-optimization leaves the strategies unchanged.

The optimal AIR given the optimal risk exposure leads to the following corollary.

Corollary 2.1. The optimal AIR for the optimal Merton stock exposure is

$$
a_{0}^{*}\left(h \mid w^{*}\right)= \begin{cases}r+\frac{1}{\gamma}(\beta-r)-\frac{1}{2 \gamma}\left(\frac{1}{\gamma}-1\right) \lambda^{2} & \text { if } \gamma>0, \gamma \neq 1, \\ \beta & \text { if } \gamma=1,\end{cases}
$$

and the AIR that leads to constant expectations is

$$
\bar{a}_{0}\left(h \mid w^{*}\right)= \begin{cases}r+\frac{\lambda^{2}}{\gamma} & \text { if } \gamma>0, \gamma \neq 1, \\ r+\lambda^{2} & \text { if } \gamma=1 .\end{cases}
$$

Proof. Plugging the optimal exposure $w^{*}$ from (2.6) into (2.27) and (2.14) gives $a_{0}^{*}\left(h \mid w^{*}\right)$ and $\bar{a}_{0}\left(h \mid w^{*}\right)$, respectively.

Remark 2.3. Both the optimal risk exposure and the optimal AIR can be solved for other utility functions as well. Karatzas and Shreve (1998)'s Theorem 3.7.3 shows the general representation of the optimal consumption. For the required technical assumptions, we refer to their Chapter 3. Both the optimal risk exposure and the AIR are implied by the optimal consumption that is obtained via the martingale method. We have, essentially, used the Hamilton-Jacobi-Bellman method in the proof of Proposition 2.2 for the special case of CRRA utility and a geometric Brownian motion for the stock price process. 
A main difference between $a^{*}$ and $\bar{a}$ in Corollary 2.1 is that the optimal one includes the individualistic risk aversion level and subjective discount rate which are part of one's individual preferences. If the subjective discount rate is higher than the risk-free rate, then the cost of waiting is higher than the reward of waiting. Therefore, a higher utility is obtained by immediate consumption which coincides with allocating less to future payments, that is, a higher AIR and vice versa. For logarithmic utility, the income effect and substitution effect cancel out the risk-free rate term of the optimal AIR. Moreover, it can be seen that for large risk aversion the optimal exposure converges to zero and thus the variable annuity with either AIR boils down to a fixed annuity.

By comparing the two AIRs, we can determine for which values the individual prefers increasing, decreasing or constant expected pension payments. By definition if $a_{0}^{*}\left(h \mid w^{*}\right)=\bar{a}_{0}\left(h \mid w^{*}\right)$, then the expected pension payments are constant, while for $a_{0}^{*}\left(h \mid w^{*}\right)<\bar{a}_{0}\left(h \mid w^{*}\right)$, less is allocated to early buckets implying an increase in expectation throughout the lifetime and vice versa. Thus, the optimal expected pension payments for the CRRA investor are either decreasing, constant or increasing for the following parameter values:

$$
\frac{1+\gamma}{2 \gamma} \lambda^{2} \begin{cases}>\beta-r & \text { increasing } \\ =\beta-r & \text { constant } \\ <\beta-r & \text { decreasing }\end{cases}
$$

Proof. $a_{0}^{*}\left(h \mid w^{*}\right)<\bar{a}_{0}\left(h \mid w^{*}\right) \Leftrightarrow r+\frac{1}{\gamma}(\beta-r)-\frac{1}{2 \gamma}\left(\frac{1}{\gamma}-1\right) \lambda^{2}<r+\frac{\lambda^{2}}{\gamma}$.

If $\beta=r$, then $a_{0}^{*}\left(h \mid w^{*}\right)<\bar{a}_{0}\left(h \mid w^{*}\right)$ for any $\gamma>0$ and thus the expected pension payments are increasing through time. The more impatient, that is the higher $\beta$, the more likely the expectation is constant or decreasing.

Munk (2017) derives the optimal consumption in the Merton model as given by (2.5) and finds that instantaneous consumption is expected to increase with age, decrease with age or to be age-independent depending on which case of (2.29) holds. Realistic parameters appear to imply that the consumption increases, on average, over life.

Figure 4 depicts ${ }^{4}$ several AIRs; the dashed line shows $\bar{a}_{0}\left(h \mid w^{*}\right)$ which generates constant expected payments for different risk aversion levels of $\gamma$, and the solid line shows $a_{0}^{*}\left(h \mid w^{*}\right)$ for $\beta=2 \%$ and the dotted line for $\beta=7 \%$ which both determine the preferred wealth allocation for a CRRA investor.

If we fixed the risk aversion level to $\gamma=2.9$, the optimal risk exposure coincides with the exogenously chosen strategy of the running example which was $w=35 \%$. Since the optimal AIR based on $\beta=2 \%$ is lower than the AIR that determines constant expectations, the implied expected pension stream will be increasing through time, while the expected payments of the CRRA investor with a subjective discount factor of $7 \%$ will be decreasing every year. Figure 3 shows the expected pension payments for the $\bar{a}_{0}\left(h \mid w^{*}\right)$ and Figures 5 and 6 show this for the two optimal AIRs $a_{0}^{*}\left(h \mid w^{*}\right)$ for $\gamma=2.9$. 


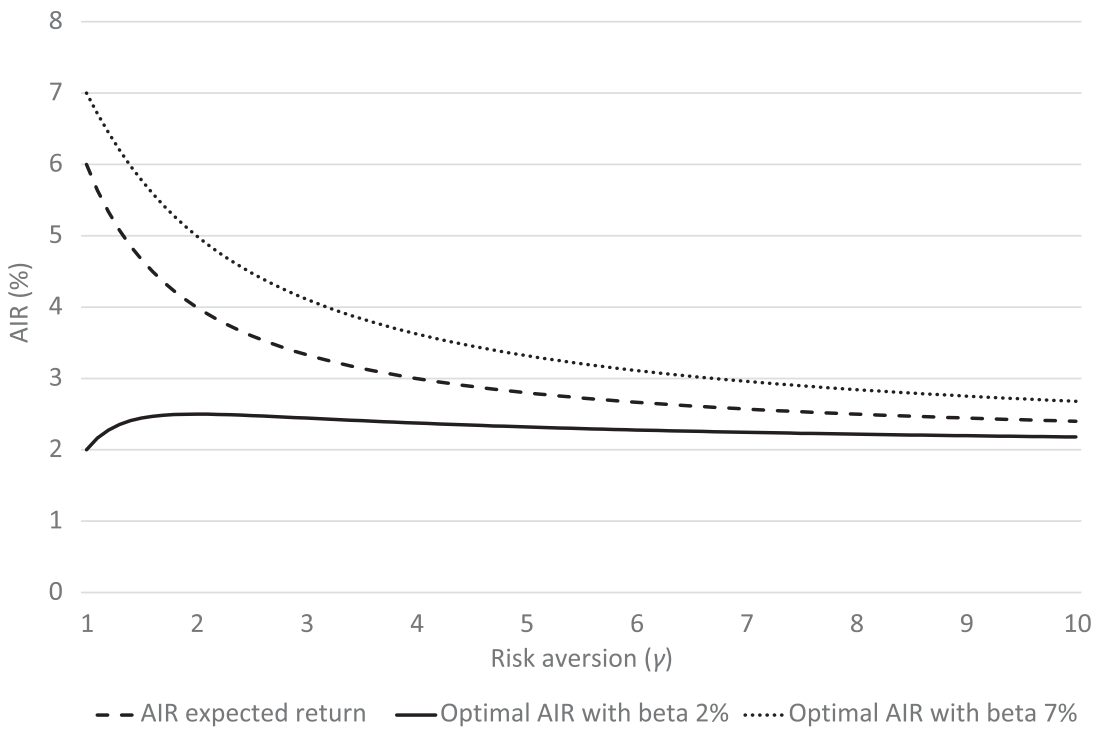

FIGURE 4: AIRs $a_{0}^{*}\left(h \mid w^{*}\right)$ with $\beta=2 \%$ or $\beta=7 \%$ and $\bar{a}_{0}\left(h \mid w^{*}\right)$.

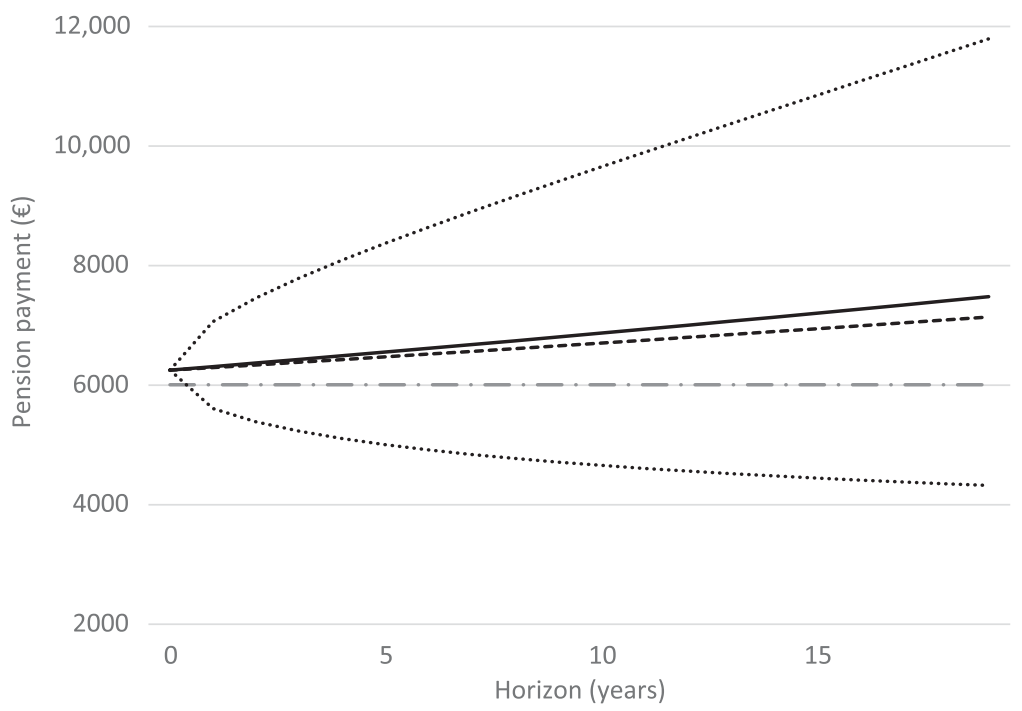

—. Fixed annuity _ Expectation ...... Pessimistic scenario ...... Optimistic scenario --- Median

FIGURE 5: Expected annuity payments for $\gamma=2.9$, where $a_{0}^{*}\left(h \mid w^{*}\right)$ with $\beta=2 \%$.

\subsection{Utility loss}

We define the total utility that the CRRA investor obtains by $U$ which is a function of the AIR and total initial wealth and given by 

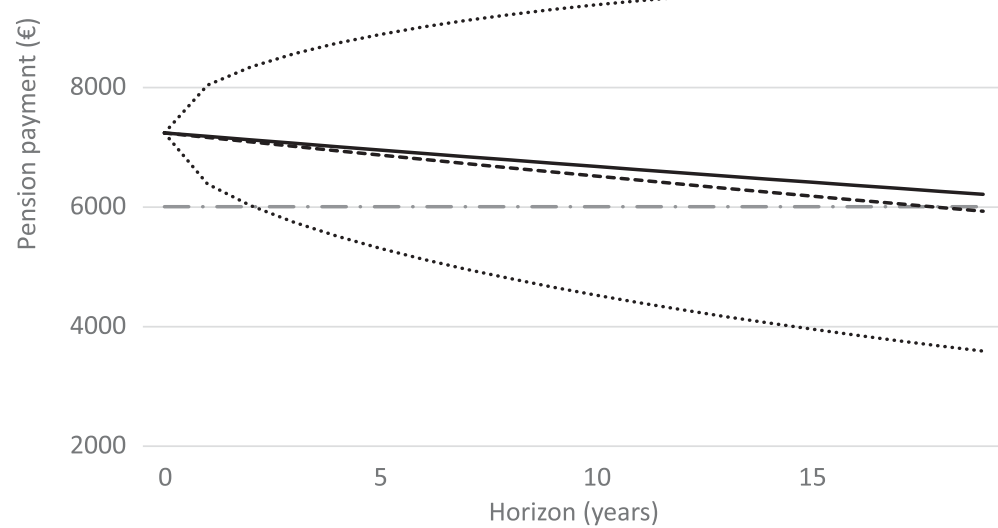

—. Fixed annuity —expectation …... Pessimistic scenario …... Optimistic scenario --- Median

FIGURE 6: Expected annuity payments for $\gamma=2.9$, where $a_{0}^{*}\left(h \mid w^{*}\right)$ with $\beta=7 \%$.

$$
\begin{gathered}
U\left(a_{0}(h \mid w), W_{0}\right)=\mathbb{E}_{0}\left[\sum_{h=0}^{H-1} \exp (-\beta h) u\left(W_{h}(h)\right) \mid W_{0}(h)=W_{0}(0) \exp \left(-h a_{0}(h \mid w)\right),\right. \\
\left.W_{0}=\sum_{h=0}^{H-1} W_{0}(h)\right] .
\end{gathered}
$$

A total wealth of $W_{0}$ and an AIR of $a_{0}(h \mid w)$ give the investor the same utility as a total - lower - wealth of $\alpha W_{0}$ and the optimal AIR of $a_{0}^{*}(h \mid w)$. We call $\alpha$ the wealth loading, which is the reduction on the total wealth the investor accepts when his wealth is distributed by the optimal AIR rather than a suboptimal one. Thus the wealth loading is implied by

$$
U\left(a_{0}(h \mid w), W_{0}\right)=U\left(a^{*}(h \mid w), \alpha W_{0}\right) .
$$

If $\alpha=1$, the investor is indifferent between the two AIRs. So the utility loss is zero. Therefore, we define the certainty equivalent utility loss as $\ell=1-\alpha$, which represents the percentage of wealth reduction due to suboptimality. By definition $0 \leq \ell \leq 1$, and the higher $\ell$, the more the investor looses due to the suboptimal AIR.

Comparing the CRRA certainty equivalents gives a closed-form expression for the utility loss. The definition of a certainty equivalent is $C E\left(a_{0}(h \mid w), W_{0}\right)=$ $u^{-1}\left(U\left(a_{0}(h \mid w), W_{0}\right)\right)$. Indifference between utilities is one-to-one related to indifference between certainty equivalents for inverse utility functions that are monotone transformations only. Therefore, (2.31) can also be stated by

$$
C E\left(a_{0}(h \mid w), W_{0}\right)=C E\left(a^{*}(h \mid w), \alpha W_{0}\right) .
$$




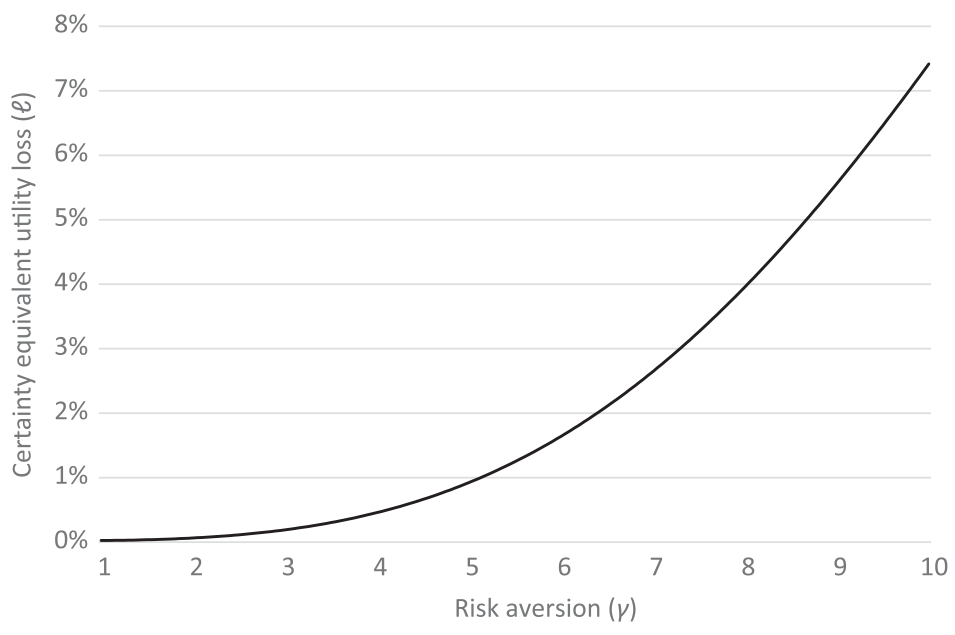

FIGURE 7: Certainty equivalent utility loss $\ell\left(\bar{a}_{0}(h \mid w), a_{0}^{*}(h \mid w)\right)$ for $w=35 \%$.

For CRRA, the certainty equivalent is given by

$$
\begin{aligned}
C E\left(a_{0}(h \mid w), W_{0}\right)= & \frac{W_{0}}{\sum_{k=0}^{H-1} \exp \left(-k a_{0}(k \mid w)\right)}\left(\sum _ { h = 0 } ^ { H - 1 } \operatorname { e x p } \left(h \left(-\beta-\left(a_{0}(h \mid w)\right.\right.\right.\right. \\
& \left.\left.\left.\left.-\left(r+w \lambda \sigma-\frac{1}{2} \gamma w^{2} \sigma^{2}\right)\right)(1-\gamma)\right)\right)\right)^{\frac{1}{1-\gamma}} .
\end{aligned}
$$

When comparing two general AIRs $a_{0,1}\left(h \mid w_{1}\right)$ with wealth $W_{0}$ and $a_{0,2}\left(h \mid w_{2}\right)$ with wealth $\alpha W_{0}$ with each other, the certainty equivalent utility loss for a CRRA investor is given by

$$
\begin{aligned}
\ell\left(a_{0,1}\left(h \mid w_{1}\right), a_{0,2}\left(h \mid w_{2}\right)\right) & =1-\alpha\left(a_{0,1}\left(h \mid w_{1}\right), a_{0,2}\left(h \mid w_{2}\right)\right) \\
& =1-\frac{C E\left(a_{0,1}\left(h \mid w_{1}\right), W_{0}\right)}{C E\left(a_{0,2}\left(h \mid w_{2}\right), W_{0}\right)},
\end{aligned}
$$

and the utility loss for logarithmic utility is obtained by the limit of $\lim _{\gamma \rightarrow 1} \frac{C E\left(a_{0,1}\left(h \mid w_{1}\right), W_{0}\right)}{C E\left(a_{0,2}\left(h \mid w_{2}\right), W_{0}\right)}$. Thus, $\ell\left(a_{0,1}\left(h \mid w_{1}\right), a_{0,2}\left(h \mid w_{2}\right)\right)$ represents the percentage of wealth that the investor with $a_{0,2}\left(h \mid w_{2}\right)$ requires less - to be indifferent in terms of utility - when the AIR is $a_{0,1}\left(h \mid w_{1}\right)$ with $100 \%$ total wealth.

Several losses of suboptimality can be analyzed since optimality is obtained for two parameters, the AIR and the exposure. In general, the following losses occur, $U\left(a_{0}^{*}\left(h \mid w^{*}\right)\right) \geq U\left(a_{0}^{*}(h \mid w)\right), U\left(a_{0}^{*}\left(h \mid w^{*}\right)\right) \geq U\left(\bar{a}_{0}\left(h \mid w^{*}\right)\right), U\left(a_{0}^{*}\left(h \mid w^{*}\right)\right) \geq$ $U\left(\bar{a}_{0}(h \mid w)\right), U\left(a_{0}^{*}(h \mid w)\right) \geq U\left(\bar{a}_{0}(h \mid w)\right)$ and $U\left(\bar{a}_{0}\left(h \mid w^{*}\right)\right) \geq U\left(\bar{a}_{0}(h \mid w)\right)$.

Figures 7 and 8 show the utility losses by comparing the optimal AIR $a_{0}^{*}(h \mid w)$ with the AIR that implies constant expectations $\bar{a}_{0}(h \mid w)$ for $r=$ $2 \%, \lambda=0.20, \sigma=20 \%, \beta=3 \%$ and an exposure of $w=35 \%$ and $w=100 \%$, respectively. For example, an investor with a risk aversion of about $\gamma=6.2$ and a risk exposure of $w=100 \%$ receives equal utility from $W_{0}=€ 100,000$ 


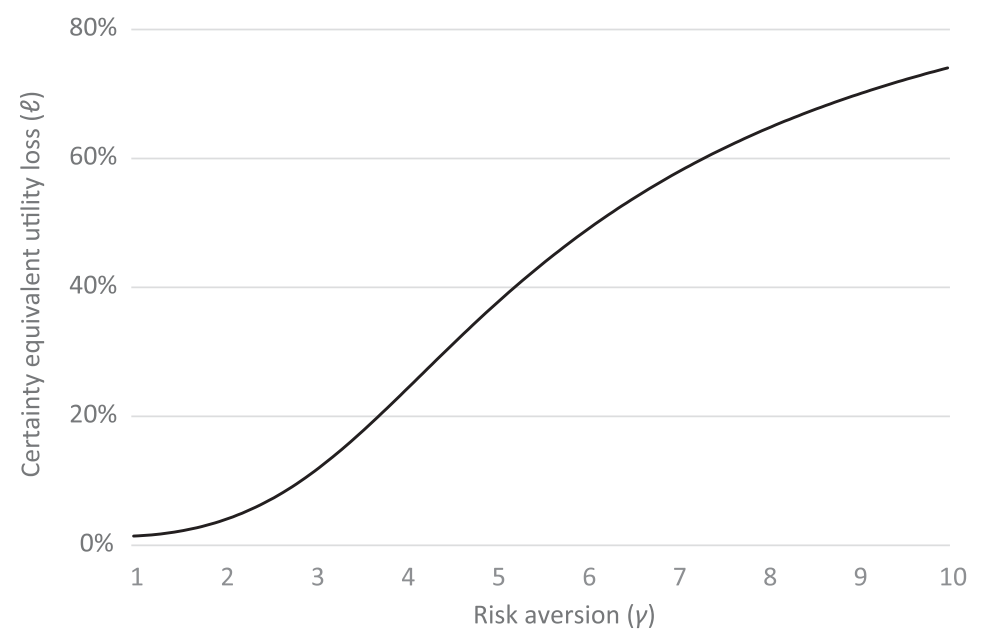

FIGURE 8: Certainty equivalent utility loss $\ell\left(\bar{a}_{0}(h \mid w), a_{0}^{*}(h \mid w)\right)$ for $w=100 \%$.

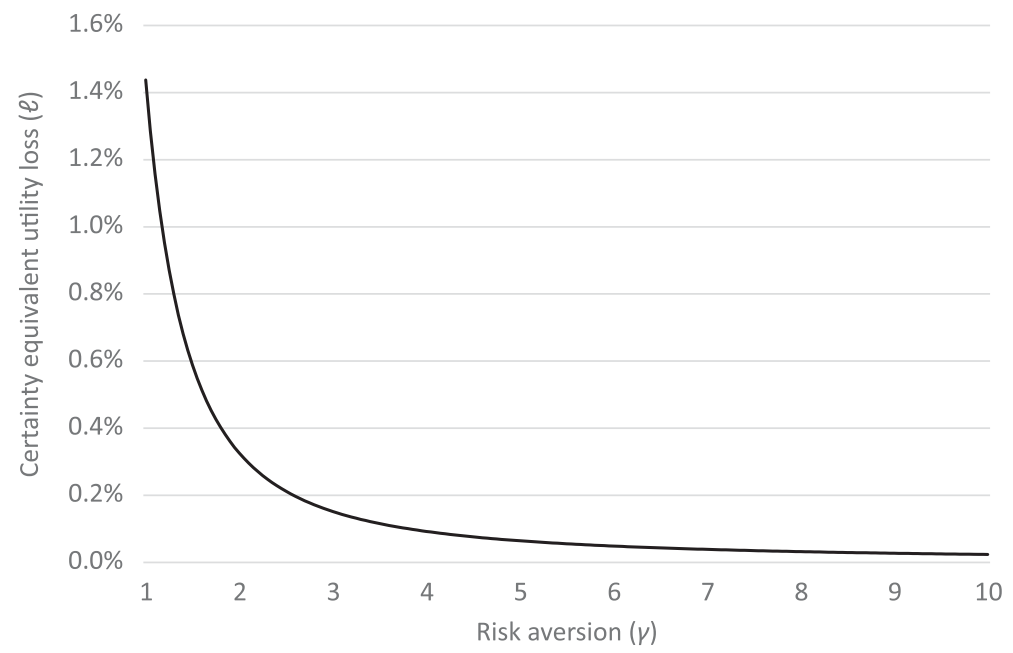

FIGURE 9: Certainty equivalent utility loss $\ell\left(\bar{a}_{0}\left(h \mid w^{*}\right), a_{0}^{*}\left(h \mid w^{*}\right)\right)$.

and a constant pension in expectation or from $W_{0}=€ 50,000$ and the optimal AIR while if $w=35 \%$, the utility loss implies $W_{0}=€ 98,200$.

Figure 9 shows the utility loss $\ell$ for the optimal risk exposure $w^{*}$ for different levels of risk aversion $\gamma$, that is, by comparing $a_{0}^{*}\left(h \mid w^{*}\right)$ with $\bar{a}_{0}\left(h \mid w^{*}\right)$. The optimal risk exposure, the constant Merton fraction, for each different level of risk aversion is shown in Figure 10. For very high levels of risk aversion, the optimal Merton strategy converges to no risk exposure and thus both AIRs converge to the risk-free rate implying no loss because of suboptimality. While for fixed risk exposure, a higher risk aversion implies a higher utility 


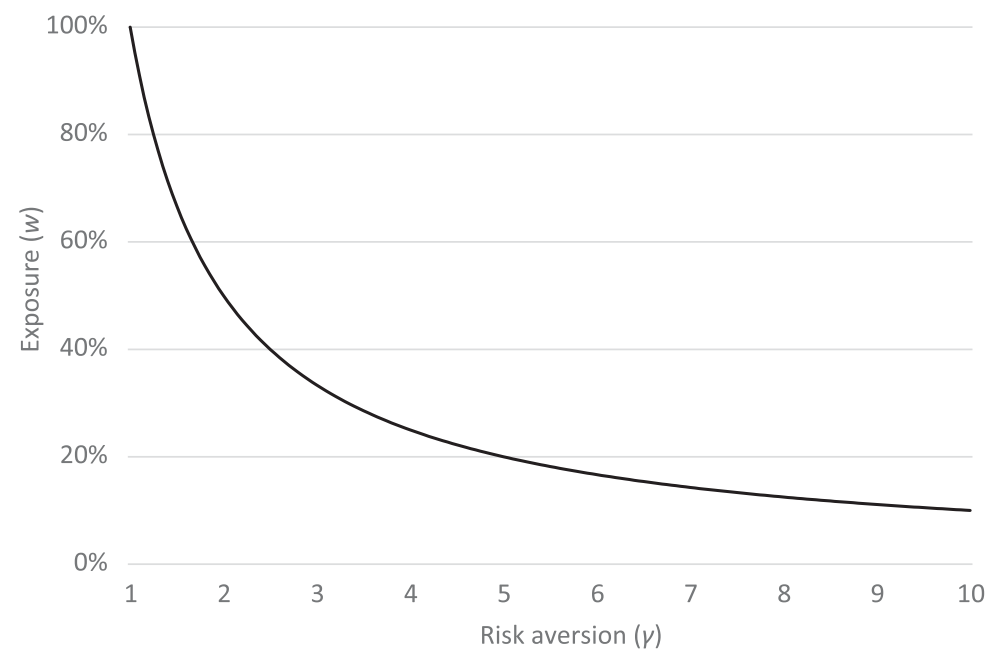

FIGURE 10: Wealth exposure $w^{*}$.

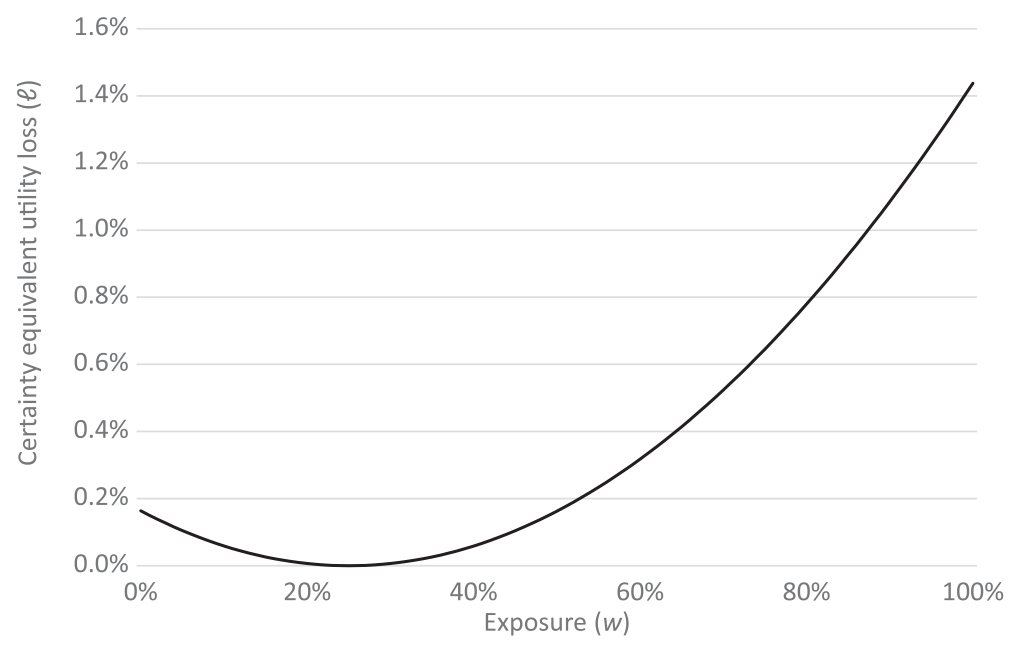

FIGURE 11: Certainty equivalent utility loss $\ell\left(\bar{a}_{0}(h \mid w), a_{0}^{*}(h \mid w)\right)$ for logarithmic utility.

loss. Moreover, when $\gamma \rightarrow 1$, the utility loss does not converge zero but to the loading of logarithmic preferences as depicted in Figure 11, which is shown for different risk exposures.

Thus for optimal risk exposure, the utility loss due to the allocation that leads to constant expected payments is small compared to the optimal AIR. Therefore, abstracting from individual measurements of the risk aversion level and subjective discount rate can be justified based on its minor impact on utility. 


\section{SMOOTHING FINANCIAL RETURNS}

If agents have habit-formation preferences, they may want to reduce yearto-year volatility in the pension payments. Utility functions of this type capture individuals who receive utility from consumption relative to a habit. It rationalizes the demand for smooth consumption as shown by Abel (1990), Constantinides (1990), Fuhrer (2000), Carroll (2000), Crawford (2010) and Davidoff et al. (2005).

The traditional view to achieve smooth consumption, that is lower yearto-year volatility, is to "smooth" financial market returns. That is, in case portfolio returns are $-20 \%$, instead of reducing the pension payment immediately by $20 \%$, it is only reduced by a fraction, say, $20 \% / 5=4 \%$. This implies that pension payments later in the retirement phase need to be cut by more than $20 \%$ to fulfill the budget constraint. Smoothing thus leads to a smaller year-to-year volatility, but the long-term volatility is larger. We derive the conceptual implications of smoothing in the framework of the discrete pension buckets and show the change in the design via the AIR that generates constant expectations.

The reduced year-to-year volatility can be achieved as follows. Recall that the initial pension payment at time 0 is given by $W_{0}(0)$. In order to have limited risk in the pension payment $W_{1}(1)$, we do not invest it according to a stock exposure $w$, as in Section 2, but with a stock exposure $w_{0}(1)=w / N$, where $N$ denotes the smoothing period, say, $N=5$ years. Subsequently, the pension wealth $W_{0}(2)$ for the pension payment $W_{2}(2)$ is invested with exposure $w_{0}(2)=2 w / N$ the first year and $w_{1}(2)=w / N$ the second year. Different smoothing mechanisms can be chosen as long as the exposure is decreased. All results, that is, formulas, below hold for general $w_{j-1}(h)$, which is the stock exposure from year $j-1$ to $j$ for the pension wealth that generates the payment in year $h$. For illustration, we provide figures based on the exposures

$$
w_{j-1}(h)=w \min \left\{1, \frac{1+h-j}{N}\right\}, j=1, \ldots, h,
$$

for given smoothing period $N$ and long-term stock exposure $w$. Figure 12 shows these stock exposure $w_{j-1}(h)$ as a function of $j$ for $h=17$.

The horizon-dependent stock exposure $w_{j-1}(h)$ induces a life-cycle-type investment strategy. That is, with smoothing, the investment mix is no longer constant over time. Note that the classical reasoning behind a life-cycle argument does not hold for the retirement phase. The idea is that human capital - future wealth from income that is still to be earned - decreases with age. As such, the fraction of savings that is allocated to investments is higher for younger workers because the absolute value of savings is relatively low. In the retirement phase, the future income does not decrease since the income at old age continues until death. However, smoothing causes a horizon-dependent investment strategy, as illustrated above. This decreasing risk exposure per 


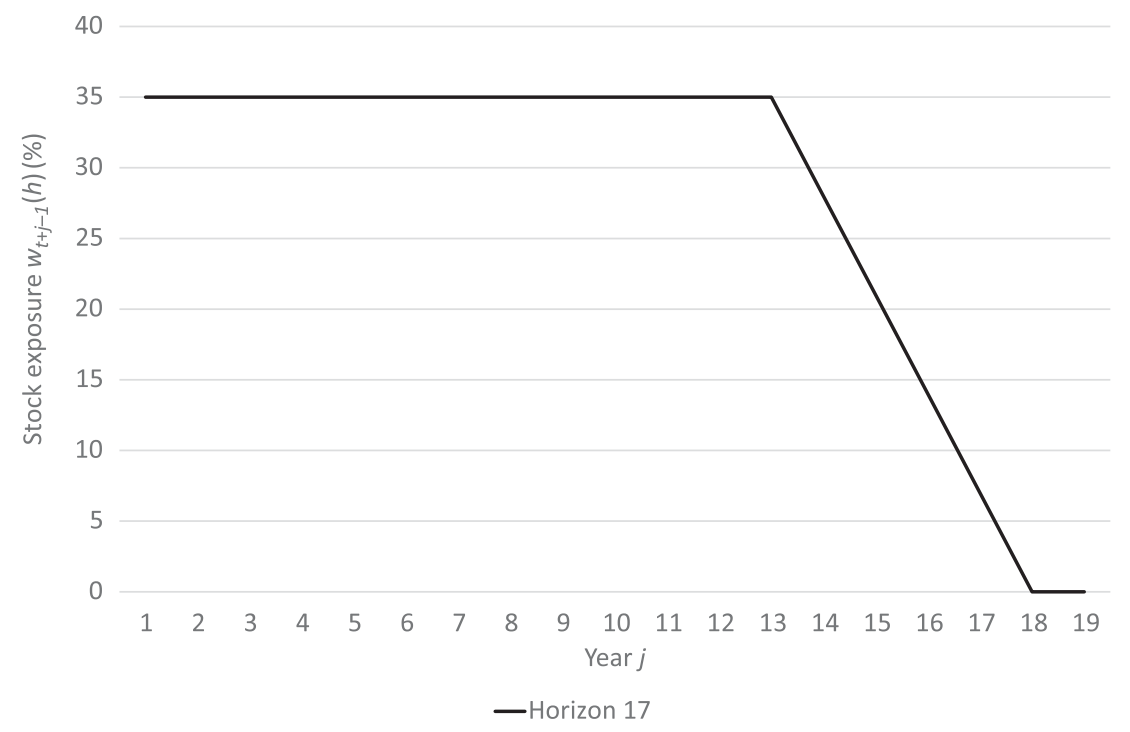

FIGURE 12: Smoothing stock exposure.

bucket is the favored design that is in line with the finding of Blake et al. (2014), who show that it is optimal to gradually exchange equity for fixed annuities in the decumulation phase for Epstein-Zin preferences. Note here that the deterministic risk exposure per bucket implies a path-dependent risk exposure in terms of the total pension wealth and thus a stochastic smoothing mechanism.

We can now calculate the distribution of the pension payment at time $h$. Again, this distribution is log-normal, but now with parameters

$$
\sum_{j=1}^{h}\left(r+w_{j-1}(h) \lambda \sigma-\frac{1}{2} w_{j-1}^{2}(h) \sigma^{2}\right)
$$

and

$$
\sum_{j=1}^{h} w_{j-1}^{2}(h) \sigma^{2} .
$$

The expected nominal pension payments, and their quantiles, can be calculated as before.

A variable annuity as specified by Equation (2.27) in Corollary 2.1 reflects the optimal design for a CRRA investor. Thus both smoothing and embedding guarantees in the design will not be preferred. Utility functions with a reference level could drive demand for smoothing or mixed annuities, where the latter combines the fixed and variable annuity according to constant proportion portfolio insurance (CPPI) to guarantee a minimum pension payment. 
In practice, smoothing mechanisms are often implemented for individual products as well as among generations. The collective product with smoothing and intergenerational risk transfers, that we do not consider here, is often based on a solidarity argument. Moreover, to protect retirees from poverty due to impatience it is for instance by Dutch national law $^{5}$ imposed that the AIR can never be chosen such that it leads to decreasing expectations. From a communicative perspective, constant expectations are usual too. Thus for the remainder of the paper, we illustrate the impact of smoothing within in the "bucket" setting for an AIR that leads to constant expectations.

\subsection{Constant expectations with smoothing}

The present setting allows for an exact derivation of the AIR that leads to pension payments that have a constant expectation. The AIR $\tilde{a}_{0}(h \mid w)$ leads to a pension payment that is constant in expected nominal terms and is given by the next proposition.

Proposition 3.1. The AIR $\tilde{a}_{0}(h \mid w)$ that leads to constant expected payments in nominal terms when financial shocks are smoothed according to (3.1) equals

$$
\tilde{a}_{0}(h \mid w)=r+\lambda \sigma \frac{1}{h} \sum_{j=1}^{h} w_{j-1}(h) .
$$

Proof. With smoothing, the expected nominal pension payment at time $h$ is given by

$$
\mathbb{E}_{0}\left[W_{h}(h)\right]=W_{0}(h) \exp \left(\sum_{j=1}^{h}\left(r+w_{j-1}(h) \lambda \sigma\right)\right) .
$$

In order to have a constant expected nominal pension payment, we must choose the AIR $\tilde{a}_{0}(h \mid w)$ such that this expectation equals $W_{0}(0)$ for all $h$. Recall, see (2.8),

$$
\frac{W_{0}(h)}{W_{0}(0)}=\exp \left(-h a_{0}(h)\right) \text {. }
$$

Thus, together with $\mathbb{E}_{0}\left[W_{h}(h)\right]=W_{0}(0)$, it follows that $\tilde{a}_{0}(h \mid w)$ is implied by the $a_{0}(h)$ that solves $\exp \left(-h a_{0}(h)\right) \exp \left(\sum_{j=1}^{h}\left(r+w_{j-1}(h) \lambda \sigma\right)\right)=1$ for a given exposure $w$.

The dash-dotted gray line in Figure 13 shows the expected pension payment and the dashed gray lines show the $5 \%$ and $95 \%$ quantiles with smoothing period $N=5$ years for a stock exposure $w=35 \%$ and the AIR equal to $\tilde{a}_{0}(h \mid w)$ of Proposition 3.1. The black dotted and black solid lines are obtained without smoothing, similar to Figure 3. 
12,000

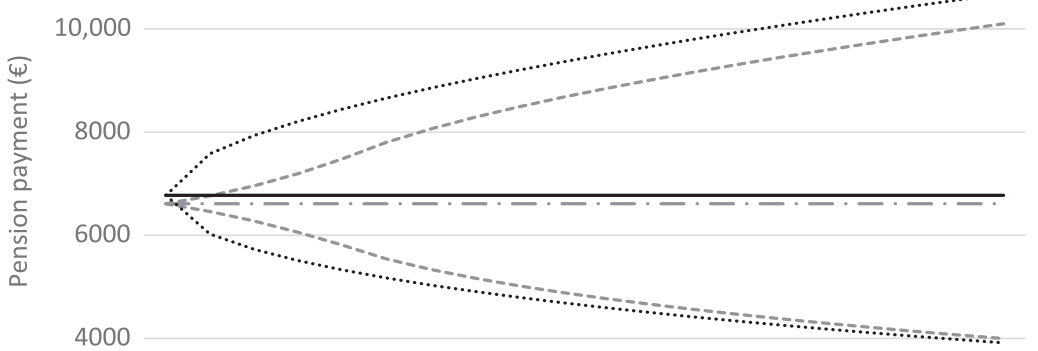

2000

$\begin{array}{llllllllllllllllllll}0 & 1 & 2 & 3 & 4 & 5 & 6 & 7 & 8 & 9 & 10 & 11 & 12 & 13 & 14 & 15 & 16 & 17 & 18 & 19\end{array}$ Horizon (years)

-. Smoothing (expected value) --- Smoothing (optimistic/pessimistic scenario)

— Without smoothing (expected value) ...... Without smoothing (optimistic/pessimistic scenario)

FIGURE 13: Smoothing with $w=35 \%, N=5$.

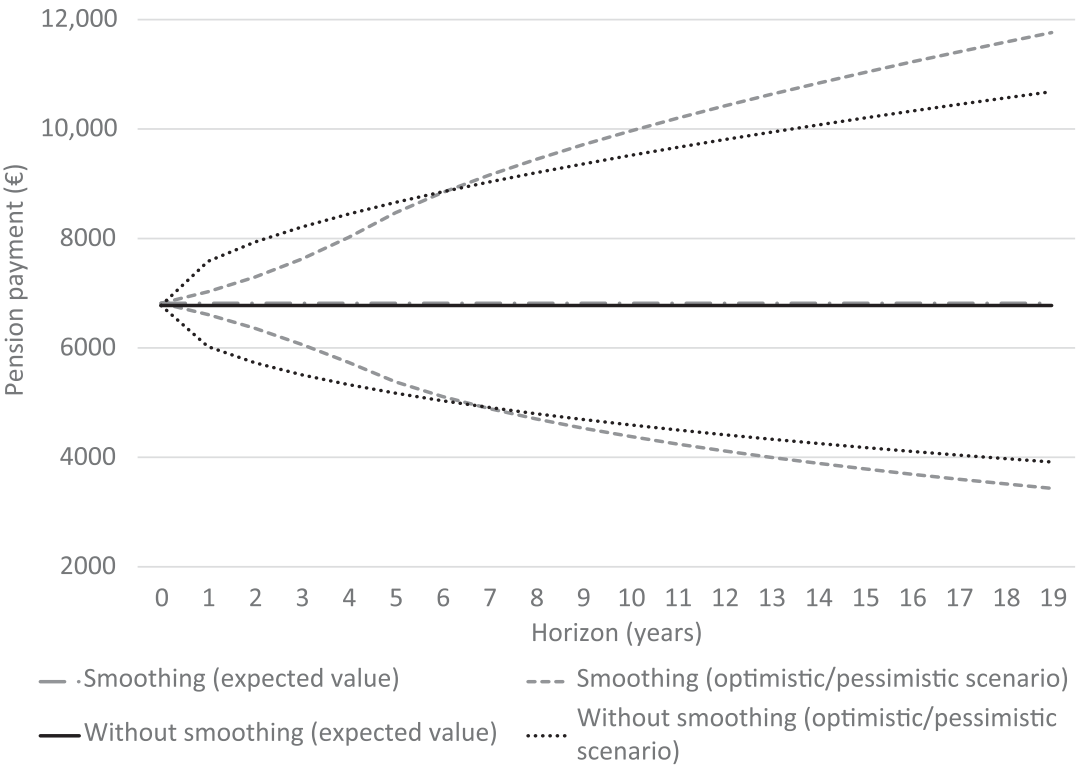

FIGURE 14: Smoothing with $w=46.5 \%, N=5$.

Because the total risk exposure is lower due to smoothing, the expected payments are lower than without smoothing. Therefore, a comparison of risk for the same level of expectations is accomplished by a stock exposure of $w=$ $46.5 \%$ with smoothing and $w=35 \%$ without smoothing, as shown in Figure 14 . 


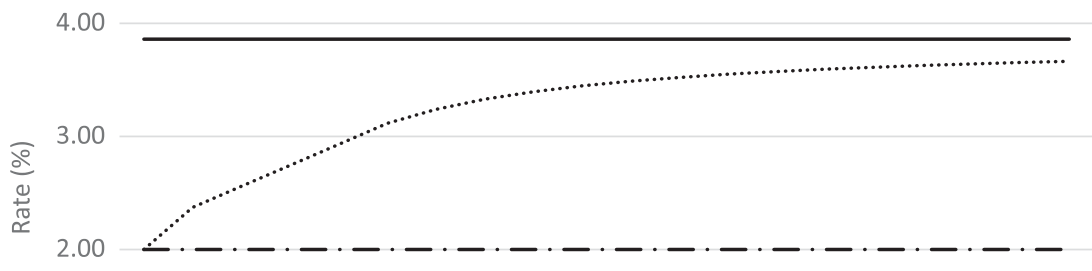

1.00

0.00

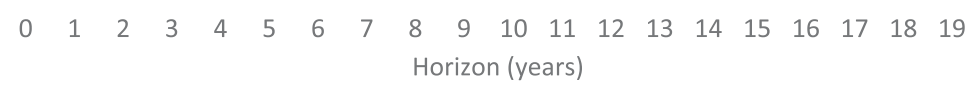

...... AIR expected return with smoothing - - Risk-free rate _-Expected return

FIGURE 15: Smoothing structure.

The dotted line in Figure 15 shows the AIR $\tilde{a}_{0}(h \mid w)$ as a function of the horizon such that the expected pension payments are constant when smoothing is applied, which is equal to the curve from Bovenberg et al. (2012). If the AIRs are set equal to the risk-free rate, as given by the dash-dotted line, the fixed annuity is obtained. The expected return with a stock exposure of $w=46.5 \%$ is the solid line.

\section{CONCLUSION}

This paper provides analytical expressions for the risk-return trade-off of variable annuities, with a special focus on the explicit allocation of initial wealth across the "pension buckets" reserved for future payments. The latter is completely determined by the AIR and relates to the consumption portfolio problem. This conceptual division provides useful insights by analyzing different AIRs. We derive the AIR that leads to constant expected pension payments as well as the optimal AIR for an investor with CRRA preferences. The utility loss between these two is small when the risk exposure is optimal, that is for the Merton fraction. We also consider the situation where financial market returns may be smoothed over the remaining retirement period. In order to obtain, in a contract with smoothing, a constant expected nominal pension, the AIR has to be horizon dependent. Other insights that we obtain from investigating the effect of the AIR on the variable annuity is that the allocation's sensitivity on the payments toward the end of life is large while early or intermediate expected payments are hardly affected by the AIR. Moreover, we show that 
variable annuities do not solve conversion risk since we find that shocks in the risk-free rate have the same effect for variable and fixed annuities.

\section{NOTES}

1. For instance, variable annuities entered the Dutch market since the Improved Defined Contribution Scheme Act of 2016 and the Australian market has introduced Comprehensive Income Products for Retirement (CIRPs).

2. Mortality could be incorporated by multiplying each "bucket" $W_{0}(h)$ reserved for the pension payment in year $h$ by the survival probability from 0 to $h$. For the impact of longevity risk, see Balter et al. (2019).

3. There is only a small effect that may lead to some protection. Under the empirically hard to defend assumption that lower interest rates $r$ imply increased prices-of-risk $\lambda$, some protection is provided. But even if this assumption is true, such protection only pertains to the risky investment in the variable annuity.

4. For the parameter assumptions of the running example, that is, $\mu=6 \%, r=2 \%, \sigma=20 \%$ and $\lambda=0.2$.

5. Source: http://www.toezicht.dnb.nl/2/50-235784.jsp

\section{REFERENCES}

ABEL, A.B. (1990) Asset prices under habit formation and catching up with the Joneses. American Economic Review, 80(2), 38-42.

Bacinello, A.R., Millossovich, P., Olivieri, A. and Pitacco, E. (2011) Variable annuities: A unifying valuation approach. Insurance: Mathematics and Economics, 49(3), 285-297.

Balter, A.G., Rangvid, J. and Kallestrup-Lamb, M. (2019) The move towards riskier pensions: The importance of mortality. Working Paper.

Bauer, D., Kling, A. and Russ, J. (2008) A universal pricing framework for guaranteed minimum benefits in variable annuities. ASTIN Bulletin: The Journal of the IAA, 38(2), 621-651.

Bernard, C., HARdy, M. and MACKAy, A. (2014) State-dependent fees for variable annuity guarantees. ASTIN Bulletin: The Journal of the IAA, 44(3), 559-585.

BLAKE, D., Wright, D. and ZhANG, Y. (2014) Age-dependent investing: Optimal funding and investment strategies in defined contribution pension plans when members are rational life cycle financial planners. Journal of Economic Dynamics and Control, 38, 105-124.

BovenberG, A., NiJman, T.E. and Werker, B. (2012) Voorwaardelijke pensioenaanspraken: Over waarderen, beschermen, communiceren en beleggen. Netspar Occasional Paper.

BRUHN, K. and STEFFENSEN, M. (2013) Optimal smooth consumption and annuity design. Journal of Banking \& Finance, 37(8), 2693-2701.

CARROLL, C.D. (2000). Solving consumption models with multiplicative habits. Economics Letters, 68(1), 67-77.

Chen, A., Hentschel, F. and Klein, J.K. (2015) A utility-and CPT-based comparison of life insurance contracts with guarantees. Journal of Banking \& Finance, 61, 327-339.

Coleman, T.F., LI, Y. and PAtron, M.-C. (2006) Hedging guarantees in variable annuities under both equity and interest rate risks. Insurance: Mathematics and Economics, 38(2), 215-228.

Constantinides, G.M. (1990) Habit formation: A resolution of the equity premium puzzle. Journal of Political Economy, 98(3), 519-543.

Cox, J.C. and HuAnG, C.-F. (1989) Optimal consumption and portfolio policies when asset prices follow a diffusion process. Journal of Economic Theory, 49(1), 33-83.

CrAwford, I. (2010) Habits revealed. The Review of Economic Studies, 77(4), 1382-1402. 
Davidoff, T., Brown, J.R. and Diamond, P.A. (2005). Annuities and individual welfare. American Economic Review, 95(5), 1573-1590.

Dellinger, J.K. (2006). The Handbook of Variable Income Annuities. Hoboken: John Wiley \& Sons.

FUHRER, J.C. (2000). Habit formation in consumption and its implications for monetary-policy models. American Economic Review, 90(3), 367-390.

Guillén, M., JørGensen, P.L. and Nielsen, J.P. (2006). Return smoothing mechanisms in life and pension insurance: Path-dependent contingent claims. Insurance: Mathematics and Economics, 38(2), 229-252.

HornefF, W.J., Maurer, R.H., Mitchell, O.S. and Stamos, M.Z. (2009). Asset allocation and location over the life cycle with investment-linked survival-contingent payouts. Journal of Banking \& Finance, 33(9), 1688-1699.

HornefF, W.J., MaUrer, R.H., Mitchell, O.S. and Stamos, M.Z. (2010). Variable payout annuities and dynamic portfolio choice in retirement. Journal of Pension Economics \& Finance, 9(2), 163-183.

Karatzas, I. and Shreve, S.E. (1998). Methods of Mathematical Finance. New York: Springer-Verlag.

KLING, A., RUEZ, F. and RUSS, J. (2011). The impact of stochastic volatility on pricing, hedging, and hedge efficiency of withdrawal benefit guarantees in variable annuities. ASTIN Bulletin: The Journal of the IAA, 41(2), 511-545.

KLING, A., RUSS, J. and SCHILLING, K. (2014). Risk analysis of annuity conversion options in a stochastic mortality environment. ASTIN Bulletin: The Journal of the IAA, 44(2), 197-236.

Koijen, R.S., NiJMan, T.E. and Werker, B.J. (2011) Optimal annuity risk management. Review of Finance, 15(4), 799-833.

MAHAYNI, A. and SCHNEIDER, J.C. (2012) Variable annuities and the option to seek risk: Why should you diversify? Journal of Banking \& Finance, 36(9), 2417-2428.

Maurer, R., Mitchell, O.S., Rogalla, R. and Siegelin, I. (2016) Accounting and actuarial smoothing of retirement payouts in participating life annuities. Insurance: Mathematics and Economics, 71, 268-283.

MERTON, R.C. (1969) Lifetime portfolio selection under uncertainty: The continuous-time case. The Review of Economics and Statistics, 51(3), 247-257.

MERTON, R.C. (1971) Optimum consumption and portfolio rules in a continuous-time model. Journal of Economic Theory, 3(4), 373-413.

Munk, C. (2017) Dynamic Asset Allocation. Lecture Notes, Copenhagen Business School, February 2017.

Nir malendran, M., Sher Ris, M. and HANEwAld, K. (2014). Pricing and solvency of valuemaximizing life annuity providers. ASTIN Bulletin: The Journal of the IAA, 44(1), 39-61.

PeijnenburG, K., Nijman, T. and Wer Ker, B.J. (2016). The annuity puzzle remains a puzzle. Journal of Economic Dynamics and Control, 70, 18-35.

Trottier, D.-A., Godin, F. and Hamel, E. (2018). Local hedging of variable annuities in the presence of basis risk. ASTIN Bulletin: The Journal of the IAA, 48(2), 611-646.

ANNE G. BALTER (Corresponding author)

Department of Econometrics and Operations Research

Tilburg University and Netspar

Tilburg 5037AB, The Netherlands

E-Mail:a.g.balter@tilburguniversity.edu

BAS J.M. WERKER

Department of Econometrics and Operations Research; Department of Finance Tilburg University and Netspar

Tilburg 5037AB, The Netherlands

E-Mail:werker@tilburguniversity.edu 